\title{
PREDIKSI KEBERHASILAN SISWA MENGGUNAKAN ALGORITMA DECISION TREE BERBASIS PEMROGRAMAN PYTHON
}

\author{
Dian Ade Kurnia, M.Kom \\ STMIK IKMI Cirebon
}

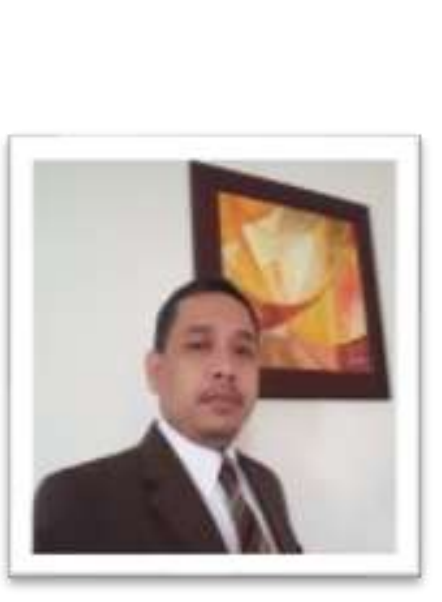

\begin{abstract}
ABSTRAK
Decision Tree merupakan model algoritma klasifikasi yang paling sederhana untuk digunakan. Decisiion Tree juga merupakan kelompok supervervised learning artinya sebuah konsep dengan pembelajaran yang terbimbing dan biasanya ditandai dengan adanya class atau label sehingga dapat digunakan untuk melakukan prediksi. Dalam kasus ini adalah akan diselesaikan sebuah permasalahan dalam memprediksi tingkat keberhasilan siswa. Dataset diambil dari https://archives.ics.uci.edu/ml/datasets/student+performance. Tujuan dari artikel ini adalah akan menghasilkan model decision tree, tingkat akurasi setelah dilakukan performance dan ditampilkan dalam bentuk
\end{abstract} grafik. Tools yang digunakan adalah bahasa pemrograman python dengan lingkugan jupyter notebook.

\section{PENDAHULUAN}

Dalam permasalahan artificial intelegence, ada suatu teknik yang dapat dilakukan oleh mesin yaitu teknik klasifikasi, begitu pula dalam kehiduapan sehari hari kita sering menangkap jutaan gambar baik itu dari buku, televisi maupun disekitar lingkungan kita. Gambar-gambar tesebut ditangkap oleh mata kita untuk membantu mengenali dan mengklasifikasikan objek.[1] .

Dalam hal ini, akan dipelajari cara membuat aplikasi untuk mengidentifikasi gambar menggunakan algoritma mesin learning. Misalnya kita memiliki gambar apel dan jeruk, dengan aplikasi tersebut akan mudah dalam membantu identifikasi apakah gambar itu mana yang menunjukan apel dan jeruk. Hal tersebut dinyatakan bahwa aplikasi dapat melakukan sebuah klasifikasi objek. Jenis klasifikasi ini disebut sebagai klasifikasi biner, artinya mengklasifikasi objek dari himpunan tertentu ke dalam dua kelompok. Dengan kata lain , aplikasi tersebut bertujua untuk membuat algoritma dengan mempelajari perbedaan antara dua objek (apel dan jeruk) untuk membantu mengklasifikasi semua contoh dengan benar, ini disebut dengan Supervised Learning (Pembelajaran Terbimbing).

Klasifikasi juga dapat terapkan tidak hanya pada objek gambar namun juga objek data dari sebuah tabel, misalnya klasifikasi algoritma dalam pengambilan keputusan menggunakan model Decision Tree. Artikel ini akan membahas tentang penggunaan model Decision Tree terhadap data kinerja siswa untuk memprediksi apakah seoarang anak akan berhasil di sekolah. Implementasi model ini menggunakan bahasa pemrograman python dengan lingkunga Jupyter Notebook. 


\section{PEMBAHASAN}

Pada bagian ini akan dibahas mengenai penggunaan Decision Tree untuk memprediksi kinerja siswa menggunakan kinerja sebelumnya. Akan dipergunakan dataset siswa yang diambil dari repositori mesin learning UC dengan alamat https://archives.ics.uci.edu/ml/datasets/student+performance

Tujuan dari artikel ini adalah untuk memprediksi apakah siswa lulus atau gagal. Dataset berisi data sekitar 649 dengan 30 atribut untuk setiap siswa. Atribut-atribut yang ada lebih dari satu katagori, kata dan frase serta atribu numerik. Sehingga atribut ini akan menjadi masalah yang harus diperbaiki, jadi harus mengubah atribu kata dan frasa mejadi tipe numerik.

Dibawah ini menunjukan bagian pertama dari data yang ada :

\begin{tabular}{|c|c|c|c|c|c|c|c|c|c|c|c|c|c|c|c|c|c|c|c|}
\hline Groul & has & 48 & aldrest & fansalis & nulea & Neats & feds & Meh & nats & rawen & fuardian & traseiflian: & netations & whe: & ftansues & gaiat & aabulies & nutsery & liepes \\
\hline 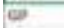 & ir & & ia $u$ & en & $\wedge$ & & $A$ & At at freme & reasher & auves & mather & 2 & 2 & $a \mathrm{men}$ & nw & ni & ne & pen & pes \\
\hline 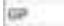 & , & & by & on & + & & 1 & 1. Shenter & ethen & cmuss & tertar & a & $z$ & 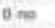 & 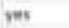 & me & ne & $n$ & $p$ \\
\hline$\omega$ & $s$ & & $15 \mathrm{u}$ & is & t & & 1 & I theme & other & sther & mether & I & 2 & oyet & ne & ne & nen & ver & $m$ \\
\hline$\theta$ & 5 & & is U & m & T & & 4. & 2 hesinh & services & mane & moither & 1 & 1 & $0 \mathrm{~m}$ & ves & me & yes & ver & vet \\
\hline$\omega$ & $s$ & & to 4 & G & $T$ & & ) & Tother & sthes & homen & therer & 1 & 2 & 000 & ien & ne & ne & ven & in \\
\hline$\omega$ & M & & $10 \mathrm{v}$ & (E) & $t$ & & 4 & inerices & athe & sesulacine & inether & 1 & $z$ & $0=0$ & in & no & yes & yes & ven \\
\hline$\omega$ & $\mu$ & & $10 \mathrm{v}$ & LES & T & & 2 & 2 other & ape & nome & mathe & 1 & 2 & 000 & no & no & no & yes & ves \\
\hline$\omega$ & , & & 17) $\mathrm{u}$ & Gr3 & $A$ & & 4 & 4 other & seacher & nome & mether & 2 & $z$ & 0 yei & wis & no & $\infty$ & in & pes \\
\hline$\infty$ & M & & isu & is & $A$ & & 3 & 2 seritias & othe & tome & mothe & 2 & I & 0 no & pet & no & no & yes & pest \\
\hline$\omega$ & M & & $\Delta u$ & on & T & & 3 & A ather & ether & hame & methe & $i$ & $z$ & $\theta \times$ & pai & ne & nes & yes & pes \\
\hline$\infty$ & r & & Du & ets & t & & 4 & A twecher & healih & moulest & mather & 1 & 2 & a to & vet & ne & $=$ & vei & net \\
\hline$\omega$ & , & & is $u$ & an & I & & 2 & 1 tentiat & athe & wpulatari & fother & 1 & , & $8 \mathrm{na}$ & vet & ne & yen & ver & $m$ \\
\hline 0 & a & & 194 & wa & 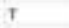 & & 4 & A hesinh & mervien & suese & fortert & 3 & 1 & 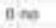 & $m$ & m & nem & $y=1$ & ine \\
\hline$\omega$ & n & & Bu $u$ & ตn & $\mathrm{r}$ & & a & I tencher & athen & caurse & mether & 3 & 2 & $\theta=0$ & $n$ & me & ne & $m$ & $y=0$ \\
\hline 0 & M. & & $15 \mathrm{~V}$ & कn & $A$ & & 2 & 2 ether & athen & hone & intrey & 1 & $i$ & $\theta \times$ & ven & min & $\infty$ & ven & $m$ \\
\hline co & F & & 100 & G) & 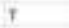 & & 4 & Theahn & other & name & Wothe & 1 & 1 & a no & res & ne & ne & yes & ien \\
\hline 6 & t & & 164 & Gr3 & T & & 4 & 4 servines & senves & reputatest & insthe & 1 & 3 & 0 No & ves & ne & yes & ves & ven \\
\hline 60 & f & & $16 \mathrm{U}$ & 63 & I & & 3 & 3 other & ather & remutacis & imenter & 1 & $z$ & oyes & ver & ne & yes & yes & vei \\
\hline$\omega$ & M & & $17 \mathrm{~V}$ & 67) & $r$ & & 3 & 2 services & semies & mone & mother & I. & 1 & $1 \infty$ & ver & net & yos & yes & yet. \\
\hline 6 & $M$ & & ite $u$ & in & I & & 4 & I hearn & eover & Bomes & teleter. & 1 & 1 & 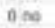 & mo & ne & ves & yes & isi \\
\hline 6 & M & & is $u$ & ars & I & & 4 & 3 losetior & ather & movilatest & mether & 1 & 2 & $\Delta$ No & ni & ae & w & wi & yes \\
\hline$a$ & M. & & Du & an & I & & 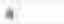 & A hearth & neallh & atier & fartert & 1 & 1 & D m & wer & wes & ne & wer & set \\
\hline
\end{tabular}

Dataset diambil dari https://archives.ics.uci.edu/ml/datasets/student+performance yaitu studentpr.csv , selanjutnya akan diolah melalui bahasa pemrograman python dengan lingkungan jupyter notebook.

Tahap awal , melakukan pemanggilan dataset student-por.csv dan menseting modul pandas, sklearn Decision Tree dan memilihi data training maupun data testing, seperti kode dibawah ini.

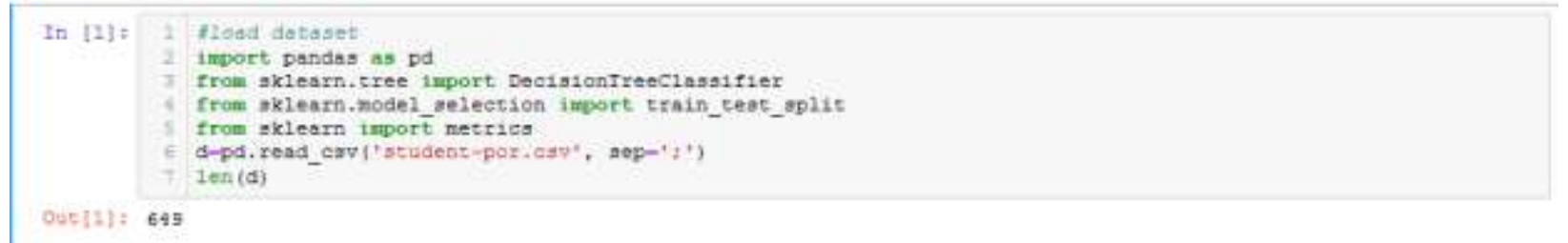

Selanjutnya diterapkan aturan seperti dibawah ini dengan menggunakan fungsi apply yang merupakan fitur dari pandas. Disini sumbu $\mathrm{x}=1$ digunakan untuk baris, dan sumbu $\mathrm{x}=0$ berlaku untuk kolom. Selanjutnya diberikan fungsi drop terhadap variabel d. Hasil dari program tersebut adalah menampilkan 5 baris pertama dan 31 kolom. 


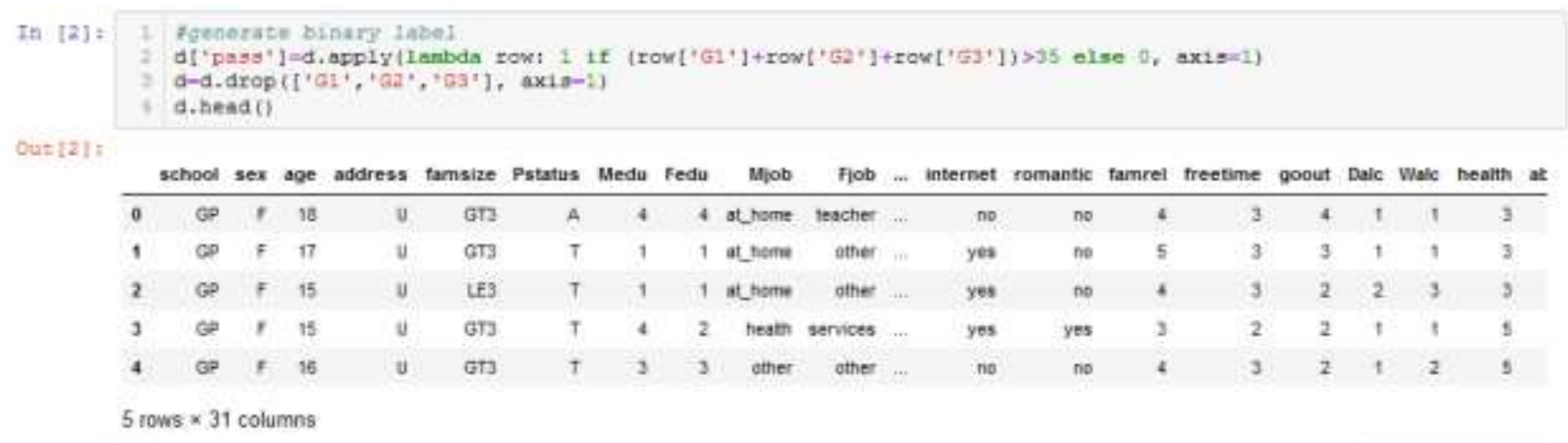

Fungsi get_dummies pada dataset tersebut adalah untuk menampilkan kolom activities_no dan activities_yes, hasilnya menunjukan bahwa terdapat 5 baris dan 57 kolom.

\begin{tabular}{|c|c|c|c|c|c|c|c|c|c|c|c|c|c|c|c|c|c|}
\hline \multirow[t]{2}{*}{ In [3]: } & \multirow[t]{2}{*}{$\begin{array}{l}1 \\
2\end{array}$} & \multicolumn{16}{|c|}{$\begin{array}{l}d=\text { pd.get_dummies (d, } \\
\text { d.head () }\end{array}$} \\
\hline & & $<$ & & & & & & & & & & & & & & & > \\
\hline Jut [3] : & & age & Medu & Fedu & traveltime & studytime & failures & famrel & freetime & goout & Dalc & $\ldots$ & activities_no & activities_yes & nursery_no & nursery_yes & higher_r \\
\hline & 0 & 18 & 4 & 4 & 2 & 2 & 0 & 4 & 3 & 4 & 1 & $\ldots$ & 1 & 0 & 0 & 1 & \\
\hline & 1 & 17 & 1 & 1 & 1 & 2 & 0 & 5 & 3 & 3 & 1 & $\ldots$ & 1 & 0 & 1 & 0 & \\
\hline & 2 & 15 & 1 & 1 & 1 & 2 & 0 & 4 & 3 & 2 & 2 & $\ldots$ & 1 & 0 & 0 & 1 & \\
\hline & 3 & 15 & 4 & 2 & 1 & 3 & 0 & 3 & 2 & 2 & 1 & $\ldots$ & 0 & 1 & 0 & 1 & \\
\hline & 4 & 16 & 3 & 3 & 1 & 2 & 0 & 4 & 3 & 2 & 1 & $\ldots$ & 1 & 0 & 0 & 1 & \\
\hline
\end{tabular}

Dari 649 record akan dibuat proporsional antara data training dan data testing, data training akan diambil sebanyak 500 record atau $77 \%$ dari total jumlah data sedangkan sisanya 149 record atau $22 \%$ dari total data.

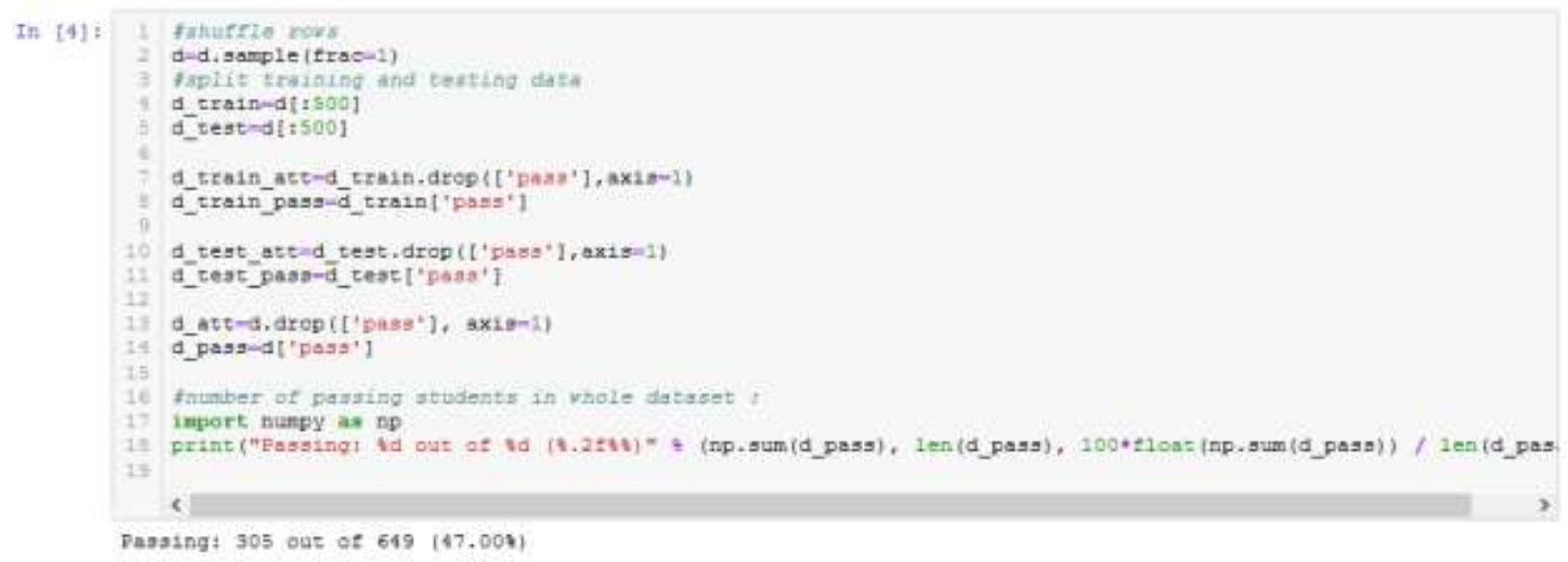

Selanjutnya kita akan membangung model klasifikasi Decision Tree melalui fungsi sklearn . Disini akan digunakan metrik entropy atau informasi untuk menentukan kapan data tersebut akan dipisahkan 


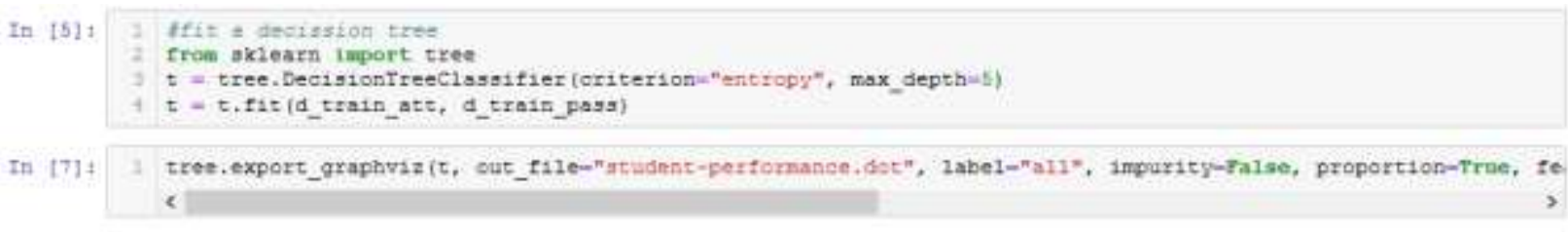

Untuk mendapatkan visualiasi model Decision Tree diperlukan visualisasi dengan menggunakan fungsi scikit-learn export_graphviz. Dibawah ini merupakan model visualisasi Decision Tree dalam lingkungan Jupyter Notebook
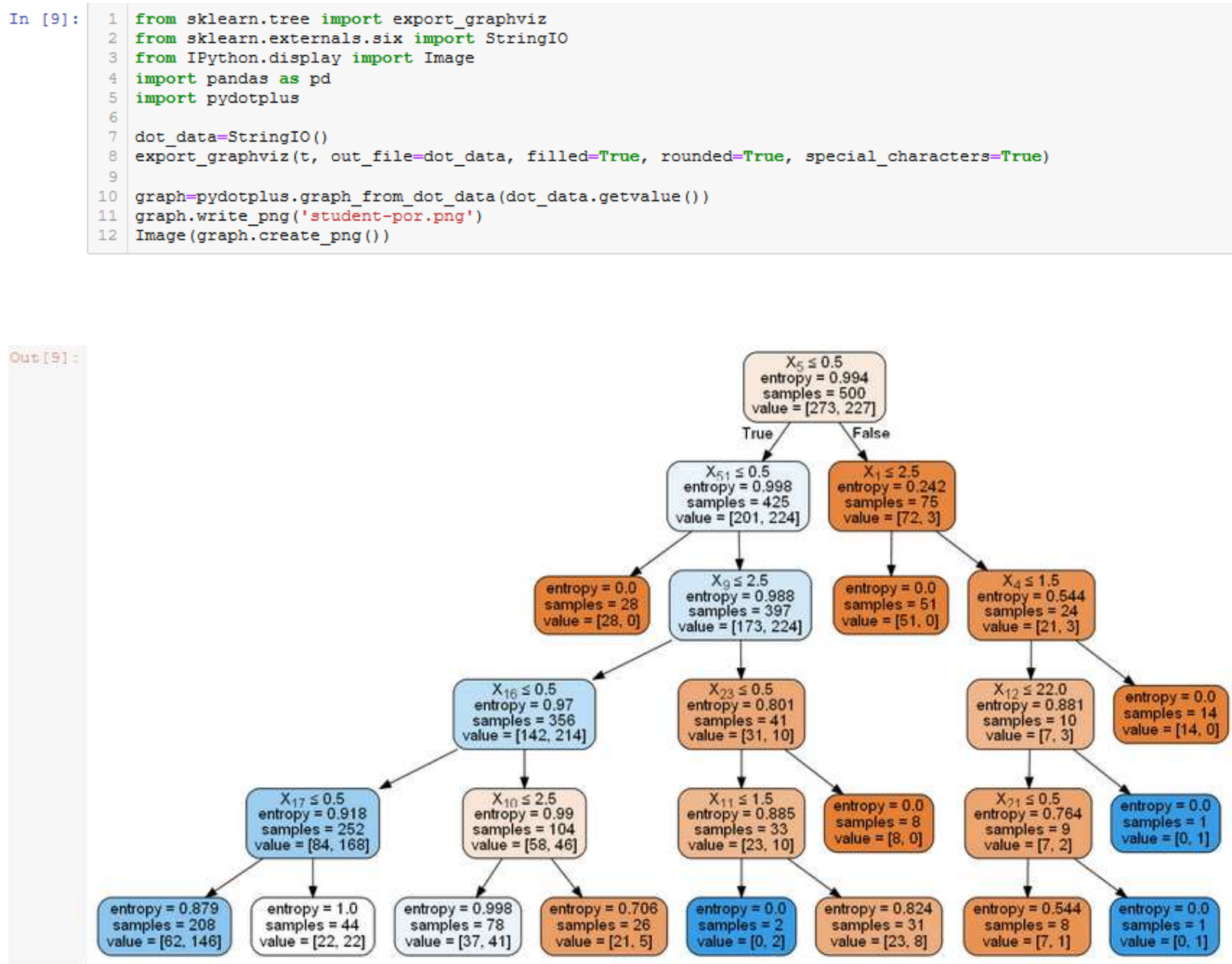

Pengujian dilakukan dengan menghasilkan score $75 \%$, dengan dataset sebelumnya.

In $[17]: \quad 1$ toscore (d_test_att, d_test_pass)

Dat:17]: 0.758

Tingkat akurasi yang dimiliki adalah sebesar 60\%, setelah dilakukan Cross Validasi terhadap seluruh dataset yang akan membagi data berdasarkan 20/80, dimana 20\% adalah data testing dan $80 \%$ adalah data training, maka hasilnya adalah $67 \%$, ini menunjukan bahwa dimilikinya dataset yang seimbang 


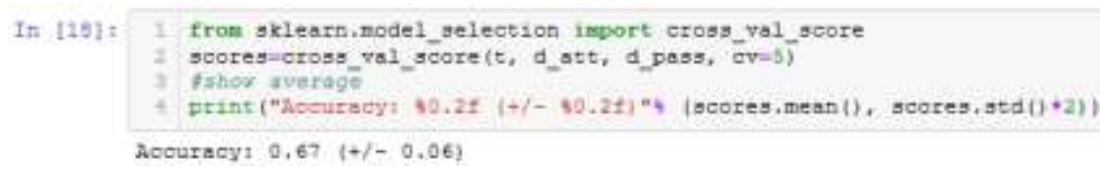

Selanjutnya digunakan nilai parameter max_depth dengan diberikan nilai 1 sampai 20 , artinya nilai tersebut memiliki tingkat kedalaman pertanyaan 20 kali atau langkah untuk mencapai simpul, dan melakukan cross validasi kembali, sehingga berdasarkan analisis ditemukan bahwa pada kedalaman 2 dan 3 akurasi adalah yang terbaik dibandigkan dengan rata rata akurasi yang ditemukan sebelumnya

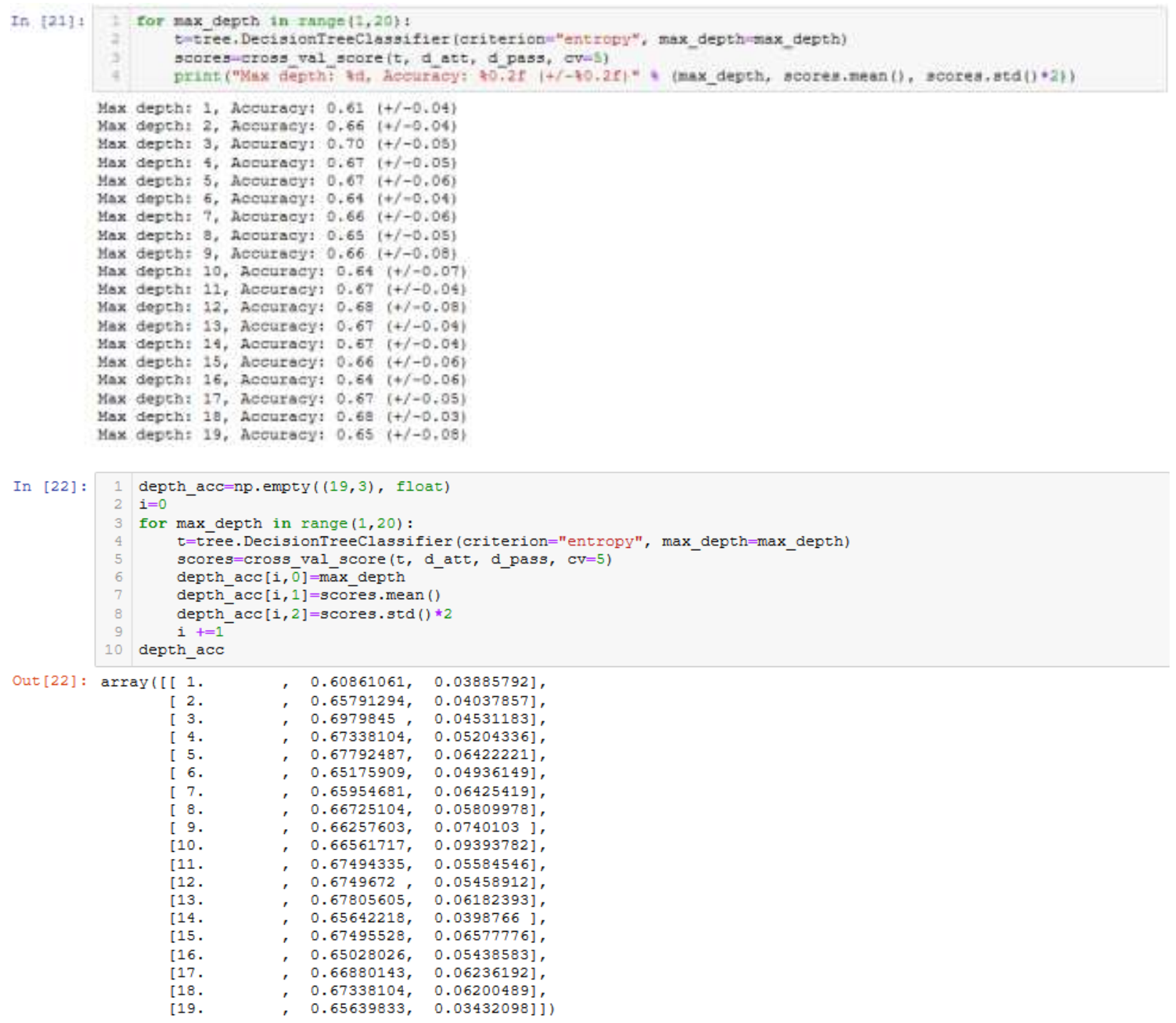

Setelah didapatkan nilai akurasi selanjutnya dapat di tampilkan dalam bentuk Grafik melalui fungsi matplotlib, seperti dibawah ini 


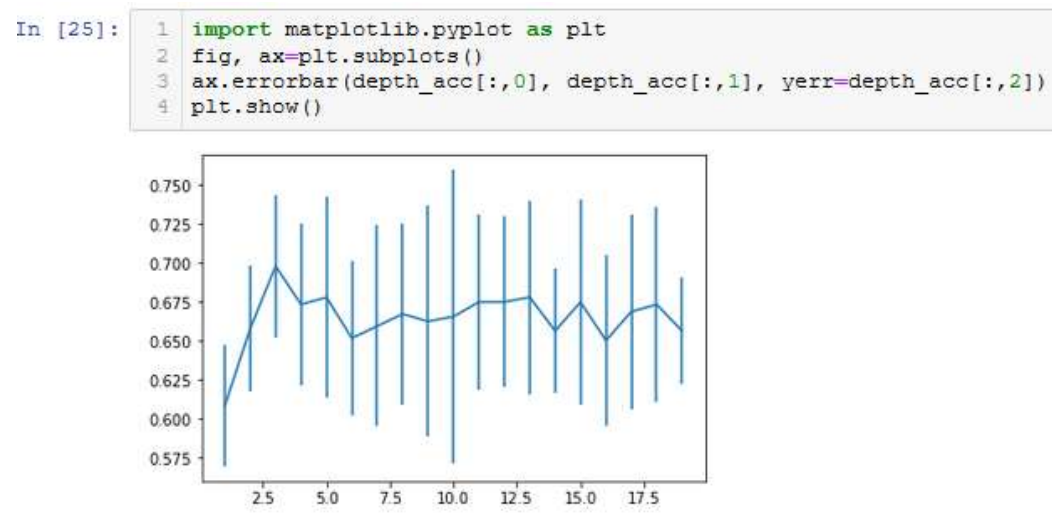

\section{RINGKASAN}

Berdasarkan pembahasan diatas, maka telah dihasilkan sebuah model algoritma klasifikasi Decision Tree dan teknik evaluasinya untuk permasalahan dalam memprediksi kinerja siswa di sekolah.

\section{DAFTAR PUSTAKA}

[1] J. Eckroth, Python Artifical Intelegence Projects for Beginners, 2018th ed. Pack Publishing, 2018. 